\title{
Resposta de Andropogon gayanus cv. Planaltina a inoculação de micorrizas arbusculares e fertilização com fosfato de rocha
}

Newton de Lucena Costa ${ }^{1^{*}}$, Claudio Ramalho Townsend ${ }^{2}$, João Avelar Magalhães ${ }^{3}$, Valdinei Tadeu Paulino ${ }^{4}$, Antônio Neri Azevedo Rodrigues, ${ }^{5}$, Lucia Elenícia da Silva Nascimento $^{6}$, Maria Jucinei de Aguiar Rodrigues ${ }^{7}$

${ }^{1}$ Eng. Agr., D.Sc., Embrapa Roraima. Boa Vista, Roraima.

${ }^{2}$ Zootecnista, D.Sc., Embrapa Clima Temperado. Pelotas, Rio Grande do Sul.

${ }^{3}$ Médico Veterinário, D.Sc., Embrapa Meio-Norte. Parnaíba, Piauí.

${ }^{4}$ Eng. Agr., Ph.D., Instituto de Zootecnia. Nova Odessa, São Paulo.

${ }^{5}$ Eng. Agr., M.Sc., Instituto Federal de Rondônia, Colorado do Oeste, Rondônia. Doutorando UFPR, Curitiba, Paraná.

${ }^{6}$ Especialista em Gestão Ambiental e Ecoturismo, Parnaíba, PI.

${ }^{7}$ Licenciada em Ciências Biológicas. Pós-graduanda em Gestão e Educação Ambiental, NEAD/UAB/UESPI. Luís Correia, PI.

*Autor para correspondência, E-mail:newtonlucena@yahoo.com.br

\begin{abstract}
RESUMO. Os efeitos da inoculação de micorríza arbuscular (MA) - Acaulospora muricata - e doses de fosfato natural de Araxá (0, 100 e $200 \mathrm{~kg}$ de $\mathrm{P}_{2} \mathrm{O}_{5} / \mathrm{ha}$ ), sobre o rendimento de matéria seca (MS) e absorção de nitrogênio e fósforo de Andropogon gayanus cv. Planaltina foram avaliados em experimento conduzido em casa de vegetação, utilizando-se um Latossolo Amarelo, textura argilosa previamente esterilizada. A inoculação de MA e a aplicação de fosfato de rocha, isoladas ou conjuntamente, promoveram acréscimos significativos no rendimento de MS e absorção de fósforo e nitrogênio da gramínea. A aplicação de fosfato de rocha aumentou a eficiência de resposta à inoculação de MA, não sendo detectado efeito de doses de fósforo. As taxas de colonização radicular não foram afetadas pela aplicação de fosfato de rocha.
\end{abstract}

Palavras chave: Colonização radicular, fósforo, matéria seca, nitrogênio

\section{Response of Andropogon gayanus cv. Planaltina to arbuscular mycorrhizal inoculation and rock phosphate fertilization}

\begin{abstract}
The effects of arbuscular mycorrhizal (AM) inoculation - Acaulospora muricata - and Araxá rock phosphate levels (0, 100 and $200 \mathrm{~kg}$ of $\mathrm{P}_{2} \mathrm{O}_{5} / \mathrm{ha}$ ), on dry matter (DM) yield, and nitrogen and phosphorus uptake of Andropogon gayanus cv. Planaltina, were evaluated in a glasshouse trial, utilizing a Yellow Latosol (Oxisol), clayey, previously sterilized. The AM inoculation, alone or combined with rock phosphate fertilization, promoted an increments on DM yields and nitrogen and phosphorus uptake. However, there were significant effects of phosphorus levels. Rock phosphate fertilization improved the efficiency of response to AM inoculation, occurred a synergistic effect. The root colonization did not affected by rock phosphate fertilization.
\end{abstract}

Keywords: Root colonization, phosphorus, dry matter, nitrogen

\section{Introdução}

Na região amazônica, a baixa disponibilidade de fósforo solúvel no solo é um dos fatores mais limitantes ao crescimento das plantas forrageiras. Devido ao alto custo dos fertilizantes fosfatados, métodos não tradicionais que aumentem a disponibilidade e favoreçam a absorção de fósforo são desejáveis e devem ser considerados, visando um manejo mais racional e econômico das pastagens. Nesse contexto, as associações micorrízicas surgem como uma das alternativas mais promissoras (Costa et al., 2013).

A colonização das raízes por micorrizas arbusculares (MA) resulta em modificações na fisiologia, bioquímica e nutrição mineral da planta hospedeira, especialmente no 
favorecimento da absorção, translocação e utilização de nutrientes e água. Nos solos de baixa fertilidade natural, notadamente naqueles deficientes em fósforo, as associações com MA apresentam efeitos benéficos mais acentuados (Mosse, 1973, Noda, 2009, Costa et al., 2012). Rhodes \& Gerdemann (1975) observaram que plantas colonizadas absorviam ${ }^{32} \mathrm{P}$ colocado até 8 cm de distância da superfície da raiz, devido as hifas externas do fungo funcionarem como extensão do sistema radicular, podendo absorver nutrientes além da zona dos pelos radiculares e da zona de depleção (1 a $2 \mathrm{~mm}$ ) que se desenvolve ao redor das raízes. Howeler et al. (1982), relacionando a produção de matéria seca obtida pela mandioca com o fósforo disponível no solo, observaram níveis críticos de 190 e 15 $\mathrm{mg} / \mathrm{kg}$ de fósforo (Bray II), respectivamente para plantas não inoculadas e inoculadas por MA.

O melhoramento da fertilidade do solo através da aplicação de fosfatos naturais evidencia ainda mais os efeitos positivos das MA. Segundo Barea et al. (1975), as plantas colonizadas, por apresentarem menores valores de $K_{m}$ são capazes de baixar o nível de fósforo na solução para valores inferiores aos do produto de solubilidade de compostos pouco solúveis. Deste modo, as MA ao aumentarem a absorção de fósforo solúvel, estimulam a dissociação química do fosfato para manter o equilíbrio deste na solução do solo (Barea \& Ázcon-Aguilar, 1983, Nasim, 2010).

No presente trabalho foram avaliados os efeitos da inoculação de MA e da aplicação de fosfato de rocha sobre o rendimento de forragem e composição química de Andropogon gayanus cv. Planaltina.

\section{Material e Métodos}

O ensaio foi conduzido em casa de vegetação, utilizando-se um Latossolo Amarelo, textura argilosa, fase floresta, com as seguintes características químicas: $\mathrm{pH}=4,8 ; \mathrm{P}=2 \mathrm{mg} / \mathrm{kg}$; $\mathrm{Ca}+\mathrm{Mg}=1,7 \mathrm{cmol}_{\mathrm{c}} / \mathrm{dm}^{3} ; \mathrm{Al}=2,6 \mathrm{cmol}_{\mathrm{c}} / \mathrm{dm}^{3} \mathrm{e}$ $\mathrm{K}=83 \mathrm{mg} / \mathrm{kg}$. O solo foi coletado na camada arável (0 a $20 \mathrm{~cm})$, destorroado e peneirado em malha de $6 \mathrm{~mm}$, sendo a seguir esterilizado em autoclave à $110^{\circ} \mathrm{C}$, por uma hora, a vapor fluente e pressão de 1,5 atm.

O delineamento experimental foi em blocos casualizados com três repetições. Os tratamentos consistiram da inoculação de uma espécie de MA (Acaulospora muricata) e três doses de fosfato de rocha $\left(0,100\right.$ e $200 \mathrm{~kg}$ de $\left.\mathrm{P}_{2} \mathrm{O}_{5} / \mathrm{ha}\right)$, aplicado sob a forma de fosfato natural de Araxá (28\% de $\mathrm{P}_{2} \mathrm{O}_{5}$ total, $6 \%$ de $\mathrm{P}_{2} \mathrm{O}_{5}$ solúvel, $43 \%$ de $\mathrm{CaO}$ ).

Cada unidade experimental constou de um vaso com capacidade para $3,0 \mathrm{~kg}$ de solo seco. A inoculação da MA foi realizada adicionando-se $10 \mathrm{~g}$ de inóculo/vaso (raiz + esporos + solo), contendo aproximadamente 500 esporos $/ 50 \mathrm{~g}$ de solo, o qual foi colocado numa camada uniforme cerca de $5 \mathrm{~cm}$ abaixo do nível de plantio. Aplicou-se $5 \mathrm{ml}$ de uma suspensão de solo livre de esporos e micélios, a fim de assegurar a presença de outros microrganismos naturais do solo. As doses de fosfato de rocha foram aplicadas antes da semeadura e uniformemente misturadas com o solo. O plantio foi realizado com sementes previamente lavadas com hipoclorito de sódio. Após o desbaste, deixaramse três plantas/vaso. O controle hídrico foi feito diariamente, através da pesagem dos vasos, mantendo-se o solo em $80 \%$ de sua capacidade de campo.

Após doze semanas de cultivo, as plantas foram cortadas rente ao solo, postas para secar em estufa à $65^{\circ} \mathrm{C}$, por 72 horas, sendo a seguir pesadas e moídas em peneira de $2,0 \mathrm{~mm}$. As concentrações de fósforo e nitrogênio foram quantificadas pelo método descrito por Tedesco (1982). As taxas de colonização radicular foram avaliadas através da observação, ao microscópio, de 25 fragmentos de raízes com $2 \mathrm{~cm}$ de comprimento, clarificadas com $\mathrm{KOH}$ e tingidas por azul de tripano em lactofenol, segundo a técnica de Phillips \& Hayman (1970).

\section{Resultados e Discussão}

Os rendimentos de matéria seca (MS) da gramínea, em função dos tratamentos aplicados estão apresentados na Tabela 1. A inoculação de MA proporcionou um incremento de $207 \%$ na produção de forragem, comparativamente ao tratamento testemunha. A aplicação de fosfato de rocha não afetou $(\mathrm{P}>0,05)$ os rendimentos de MS, independentemente da dose utilizada e da inoculação de micorriza. Resultados semelhantes foram relatados por Howeler et al. (1982), após avaliar o efeito de MA, na presença ou não de adubação fosfatada, em A. gayanus cv. Planaltina. Segundo Ázcon-Aguilar \& Barea (1978), bactérias solubilizadoras de fosfatos estão presentes na rizosfera micorrízica atuando sinergicamente com os endófitos. Deste modo, as MA ao incrementarem a absorção de fósforo, 
favorecem a dissociação química do fosfato insolúvel visando estabilizar a concentração deste na solução do solo (Barea \& Ázcon-Aguilar, 1983).

Jehne (1980) observou que as espécies de MA apresentam especificidade em relação às fontes de fósforo aplicadas, o que pode influenciar diretamente na eficiência destas. Miranda et al. (1984) verificaram interação significativa entre doses de fósforo e inoculação de MA, a qual foi explicada, em parte, pela melhor eficiência de absorção de fósforo e transformação em rendimento de MS das plantas de sorgo inoculadas, na dose de $25 \mathrm{mg} / \mathrm{kg}$ de fósforo, devido a ausência de diferenças significativas entre as doses de 25 e $50 \mathrm{mg} / \mathrm{kg}$ de fósforo, quando as plantas foram micorrizadas.

Tabela 1. Rendimento de matéria seca (MS), taxas de colonização radicular e teores e quantidades absorvidas de nitrogênio e fósforo de A. gayanus cv. Planaltina, em função da micorrização e aplicação de fosfato de rocha.

\begin{tabular}{lcccccc}
\hline Tratamentos & MS & Colonização & \multicolumn{2}{c}{ Nitrogênio } & \multicolumn{2}{c}{ Fósforo } \\
\cline { 4 - 7 } & $\mathrm{g} /$ vaso & Radicular $(\%)$ & $\mathrm{g} / \mathrm{kg}$ & $\mathrm{mg} / \mathrm{vaso}$ & $\mathrm{g} / \mathrm{kg}$ & $\mathrm{mg} / \mathrm{vaso}$ \\
\hline Testemunha & $3,44 \mathrm{~d}$ & -- & $15,6 \mathrm{a}$ & $53,66 \mathrm{~d}$ & $1,10 \mathrm{~d}$ & $3,78 \mathrm{e}$ \\
Micorriza $(\mathrm{M})$ & $7,12 \mathrm{c}$ & $48,1 \mathrm{a}$ & $13,8 \mathrm{~b}$ & $98,26 \mathrm{c}$ & $1,37 \mathrm{c}$ & $9,75 \mathrm{~d}$ \\
Fosfato $\left(\mathrm{F}_{1}\right)$ & $9,68 \mathrm{bc}$ & -- & $14,2 \mathrm{~b}$ & $137,45 \mathrm{~b}$ & $1,40 \mathrm{c}$ & $13,55 \mathrm{~cd}$ \\
Fosfato $\left(\mathrm{F}_{2}\right)$ & $12,06 \mathrm{~b}$ & -- & $13,1 \mathrm{c}$ & $157,99 \mathrm{~b}$ & $1,48 \mathrm{c}$ & $17,85 \mathrm{bc}$ \\
$\mathrm{M}+\mathrm{F}_{1}$ & $15,67 \mathrm{ab}$ & $53,5 \mathrm{a}$ & $13,9 \mathrm{~b}$ & $217,81 \mathrm{a}$ & $1,62 \mathrm{~b}$ & $21,78 \mathrm{~b}$ \\
$\mathrm{M}+\mathrm{F}_{2}$ & $18,11 \mathrm{a}$ & $50,9 \mathrm{a}$ & $13,0 \mathrm{c}$ & $235,43 \mathrm{a}$ & $1,77 \mathrm{a}$ & $32,05 \mathrm{a}$ \\
\hline
\end{tabular}

Médias seguidas de mesma letra não diferem entre si $(\mathrm{P}>0,05)$ pelo teste de Tukey

$\mathrm{F}_{1}=100 \mathrm{~kg}$ de $\mathrm{P}_{2} \mathrm{O}_{5} / \mathrm{ha}$

$\mathrm{F}_{2}=200 \mathrm{~kg}$ de $\mathrm{P}_{2} \mathrm{O}_{5} / \mathrm{ha}$

As taxas de colonização radicular não foram afetadas $(\mathrm{P}>0,05)$ pela aplicação de fosfato de rocha (Tabela 1). Provavelmente, este fato foi consequência da aplicação de doses relativamente pequenas de fósforo, já que, geralmente a adubação fosfatada, notadamente de fontes solúveis, diminui a formação de micorrizas, bem como a proliferação de esporos (Mosse, 1973, Noda, 2009). Da mesma forma, Costa et al. (1989) não detectaram efeito depressivo da aplicação de fosfato natural de Patos de Minas sobre a colonização de raízes de aveia forrageira inoculadas com Glomus macrocarpum. No entanto, a adição de superfosfato triplo reduziu significativamente as taxas de colonização radicular.

Os maiores teores de nitrogênio foram obtidos no tratamento testemunha, como consequência do efeito de concentração deste nutriente, em função da menor produção de MS. As maiores quantidades absorvidas de nitrogênio foram obtidas com a aplicação de fosfato de rocha, associada à inoculação de MA, não sendo, contudo, constatado efeito $(\mathrm{P}>0,05)$ de doses. Plantas fertilizadas com $200 \mathrm{~kg}$ de $\mathrm{P}_{2} \mathrm{O}_{5} / \mathrm{ha}$, na presença de MA, forneceram os maiores teores e quantidade absorvida de fósforo (Tabela 1). Mosse (1977) observou que plantas micorrizadas de milho, suplementadas com pequenas doses de fósforo, apresentavam melhor crescimento e absorção de nutrientes. $\mathrm{O}$ aumento na área de solo explorado parece ser o principal mecanismo responsável pelo aumento da absorção de nutrientes. Gerdemann \& Trappe (1974) verificaram que as hifas do fungo que colonizavam o córtex estendem-se no solo adjacente, podendo atingir distâncias consideráveis $(16 \mathrm{~cm})$ da superfície da raiz, aumentando, deste modo, a interface raiz-solo, além de fazer a comunicação das raízes absorventes com zonas não esgotadas em nutrientes. Para Siqueira (1983) a micorrização, geralmente, implica em aumento na taxa fotossintética, respiração e transpiração, o que pode exercer efeitos positivos sobre a absorção de nutrientes disponíveis na solução do solo.

\section{Conclusões}

1. A inoculação de MA e a aplicação de fosfato de rocha, isoladas ou conjuntamente, promoveram acréscimos no rendimento de matéria seca $\mathrm{e}$ absorção de fósforo e nitrogênio da gramínea;

2. A aplicação de fosfato de rocha aumentou a eficiência de resposta à inoculação de MA, não sendo detectado efeito significativo de doses de fósforo;

3. As taxas de colonização radicular não foram afetadas pela aplicação de fosfato de rocha. 


\section{Referências Bibliográficas}

Ázcon-Aguilar, C. \& Barea, J. 1978. Effects of interactions between different culture fractions of phosphobacteria and Rhizobium on mycorrhizal infection, growth, and nodulation of Medicago sativa. Canadian Journal of Microbiology, 24, 520-524.

Barea, J. \& Ázcon-Aguilar, C. 1983. Mycorrhizas and their significance in nodulating nitrogenfixing plants. Advances in Agronomy, 36, 154.

Barea, J., Azcon, R. \& Hayman, D.S. 1975. Possible synergistic interactions between Endogone and phosphate-solubilizing bacteria in low-phosphate soils. In: Sanders, F.E., Mosse, B. \& Tinker, P.B. (Eds) Endomycorrhizas.London.

Costa, N.L., Alcântara, V.B.G., Paulino, V.T., Townsend, C.R., Pereira, R.G.A., Magalhães, J.A., Nascimento, L.E.S. \& Rodrigues, M.J.A. 2013. Resposta de Cassia rotundifolia CIAT7792 à inoculação de micorrizas arbusculares e adubação com fosfato de rocha. Pubvet, 7, Art\#1511.

Costa, N. L., Dionísio, J. A. \& Anghinoni, I. 1989. Influência de fungos micorrízicos vesículo-arbusculares, fontes e doses de fósforo sobre o crescimento de aveia forrageira. Pesquisa Agropecuária Brasileira, 24, 979-986.

Costa, N. L., Paulino, V. T., Costa, R. S. C., Araújo Pereira, R. G., Townsend, C. R. \& Magalhães, J. A. 2012. Efeito de micorrizas arbusculares sobre o crescimento e nutrição mineral de Brachiaria brizantha cv. Marandu. Ciência Animal Brasileira, 13, 406-411.

Gerdemann, J. W. \& Trappe, J. M. 1974. Endogonaceae in the pacific Northwest. Mycological Memories, 5, 1-76.

Howeler, R., Cadavid, L. \& Burckhardt, E. 1982. Response of cassava to VA mycorrhizal inoculation and phosphorus application in greenhouse and field experiments. Plant and Soil, 69, 327-339.

Jehne, W. 1980. Endomycorrhizas and the productivity of tropical pastures: the potential for improvement and its practical realization. Tropical Grasslands, 14, 202-209.
Miranda, J.C.C., Souza, D.M.G. \& Miranda, L. N. 1984. Influência de fungos endomicorrízicos vesículo-arbusculares na absorção de fósforo e no rendimento de matéria seca de plantas de sorgo. Revista Brasileira de Ciência do Solo, 6, 19-23.

Mosse, B. 1973. Advances in the study of vesicular-arbuscular mycorrhiza. Annual Review of Phytopathology, 11, 171-196.

Mosse, B. 1977. Plant growth responses to vesicular-arbuscular mycorrhiza. $\mathrm{X}$. Responses of Stylosanthes and maize to inoculation in unsterile soils. New Phytologist, 78, 277-288.

Nasim, G. 2010. Arbuscular mycorrhizal fungi associated with tissue culture raised potato. Pakistan Journal of Botany, 42, 4215-4227.

Noda, Y. 2009. Las Micorrizas: Una alternativa de fertilización ecológica en los pastos. Pastos y Forrajes, 32, 1-1.

Phillips, J. M. \& Hayman, D.S. 1970. Improved procedures for clearing roots and staining parasitic and vesicular-arbuscular mycorrhizal fungi for rapid assessment of infection. Transactions of the British Mycological Society, 55, 158-161

Rhodes, L. \& Gerdemann, J. 1975. Phosphate uptake zones of mycorrhizal and nonmycorrhizal onions. New Phytologist, 75, 555561.

Siqueira, J.O. 1983. Nutritional and edaphic factors affecting spore germination, germ tube growth and root colonization by the vesiculararbuscular mycorrhizal fungi. Gainesville: University of Florida, Thesis Ph.D.

Tedesco, J.M. 1982. Extração simultânea de N, P, $\mathrm{K}, \mathrm{Ca}$ e $\mathrm{Mg}$ em tecido de plantas por digestão com $\mathrm{H}_{2} \mathrm{O}_{2}-\mathrm{H}_{2} \mathrm{SO}_{4}$. Porto Alegre: UFRGS, 23p. (UFRGS. Informativo Interno, 1).

Recebido em Dezembro 10, 2014

Aceito em Maio 27, 2015

License information: This is an open-access article distributed under the terms of the Creative Commons Attribution License, which permits unrestricted use, distribution, and reproduction in any medium, provided the original work is properly cited. 